Saudi Journal of Oral and Dental Research

Abbreviated Key Title: Saudi J Oral Dent Res

ISSN 2518-1300 (Print) |ISSN 2518-1297 (Online)

Scholars Middle East Publishers, Dubai, United Arab Emirates

Journal homepage: https://saudijournals.com/sjodr

\title{
Dealing with Mandibular Resorbed Ridge by Using the Neutral Zone Technique: About A Case Report
}

Yasmine Tayachi $^{{ }^{*}}$, Jamila Jaouadi ${ }^{2}$, Rabeb Bendhief ${ }^{1}$

${ }^{1}$ Resident in Prosthodontics, ${ }^{2}$ Professor in Prosthodontics, Complete Denture Department, Faculty of Dental Medicine of Monastir, Avenue Avicenne، الـ مد سد ت بر، 9105, aisinuT

DOI: $10.36348 /$ sjodr.2020.v05i02.005

| Received: 06.02.2020 | Accepted: 15.02.2020 | Published: 23.02.2020

*Corresponding author: Dr. Yasmine Tayachi

Abstract

The most difficult challenge for practitioners is to solve the problem of the loose and functional instability of the mandibular denture, particularly for patients with a severely resorbed ridge. Neutral zone technique must be relied on, to set the teeth in the space where the displacing forces of the lips, the tongue, and cheeks are balanced. It guarantees optimal prosthetic integration.

This case report describes the steps of recording this neutral zone.

Keywords: Neutral zone, piezographic impression, speech, swallowing, teeth arrangement

Copyright @ 2020: This is an open-access article distributed under the terms of the Creative Commons Attribution license which permits unrestricted use, distribution, and reproduction in any medium for non-commercial use (NonCommercial, or CC-BY-NC) provided the original author and source are credited.

\section{INTRODUCTION}

The primary objective of complete denture prosthesis is to make dentures that will satisfy the three basic requirements of the edentulous patient: maximum comfort, efficiency and aesthetics [5].

The loose and unstable lower complete denture is one of the most common problems faced by denture patients. One of the methods used to solve this problem is the neutral zone technique [6].

The effect of the neutral zone (NZ) technique on different functional aspects (masticatory performance, speech, and muscle activity) has been studied objectively [2].

The three dimensional volume of complete dentures optimally occupies an edentulous space that is substantial, in the light of the progressive changes that accompany edentulism and functional dynamics [1].

This article describes the way to register the neutral zone through piezography but also highlights how this science takes care of the edentulous area by preliminary impression.

In fact; the clinical illustration brings more details and offers a comparison between functions used and the way to optimize the success of complete dentures in Sangiuolo's CLIII.

\section{CASE REPORT}

This clinical report illustrates the management of a mandibular resorbed ridge; A 74-year-old male, who has been on antidepressants for 10 years, was referred by his dentist to the department of complete denture at the Dental Clinic of Monastir for a prosthetic rehabilitation. 


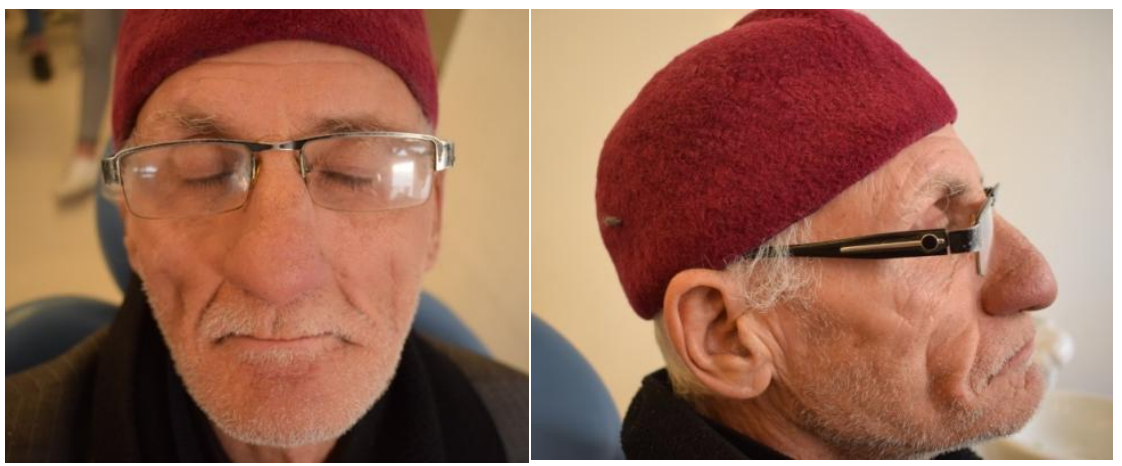

Fig-1: Front and side view

The intraoral examination revealed a favorable maxillary residual ridge, however, the mandibular one was severly resorbed.

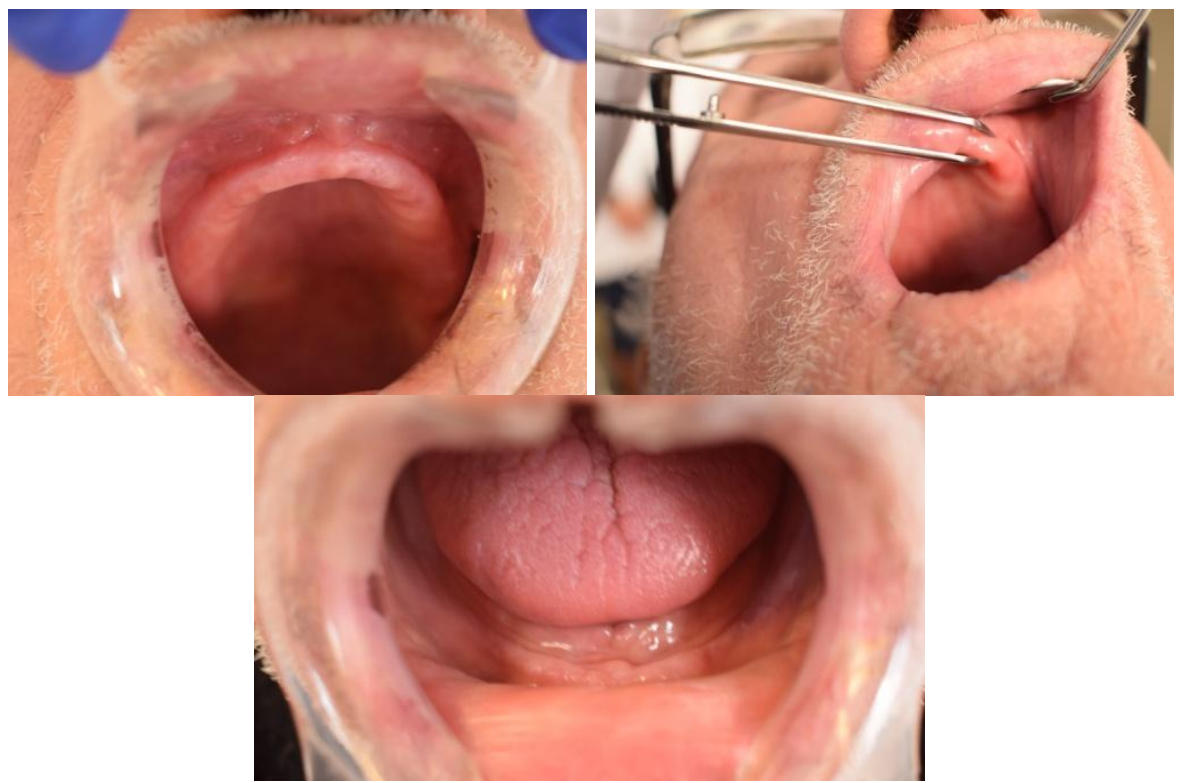

Fig-2: Intraoral examination showing a favorable maxillary residual ridge and a resorbed mandibular one

Primary impressions of the upper and lower jaws were made with irreversible hydrocolloid material and models were poured in plaster of Paris.

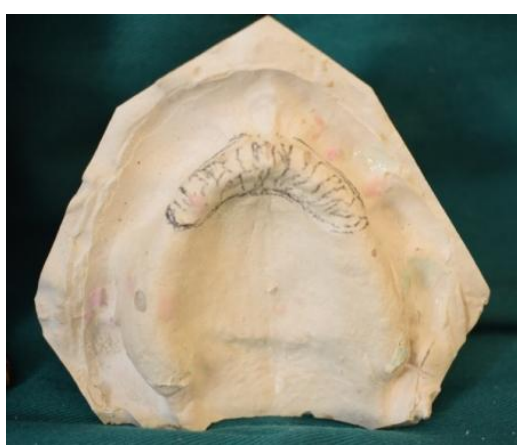

Fig-3: Primary Maxillary and Mandibular model

Then secondary impression was done in closed mouth through functional impression technique and made by polysulfide then poured with stone plaster.
The primary mandibular model was used to adjust and stabilize a metallic wire.

Moreover, flubby ridge has been hatched on the anterior zone on the maxilla ridge.

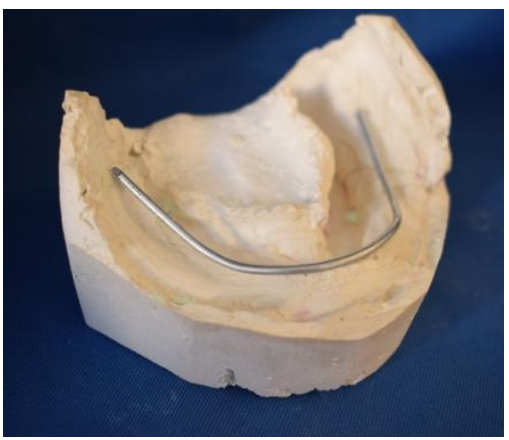

Denture bases with occlusal rim were fabricated on primary cast and Jaw relations were taken to record appropriate horizontal and vertical dimensions. 
Yasmine Tayachi et al; Saudi J Oral Dent Res, Feb 2020; 5(2): 111-119

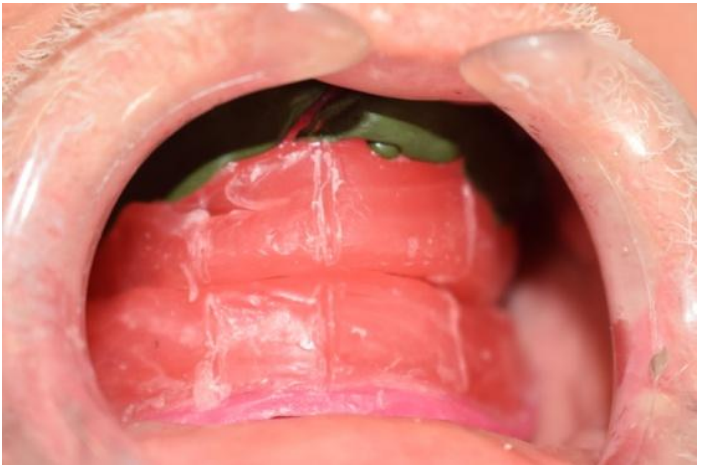

Fig-4: The occlusion record

The ideal way to proceed is to make the final impression in two steps. First, a classicimpression under correct occlusion with polyether, than spacing will be led in front of displaceable mucosa; theborder between displaceable and non-displaceable mucosa is marked on the impression and registered in a second time with a low viscosity polyether and once again under correct Jaw relations [13].

The two-step final-impression technique begins with border molding, followed by a final impression procedure.

Border molding is defined as "the shaping of impression material along with the border areas of an impression tray by functional or manual manipulation of the soft tissues adjacent to the borders to duplicate the contour and size of the vestibule". It is also defined as determining the extension of a prosthesis, by using tissue function or manual manipulation of the tissues to shape the border area of impression material. It can be accomplished by using either a sectional or a single-step technique, using different types of materials [15].
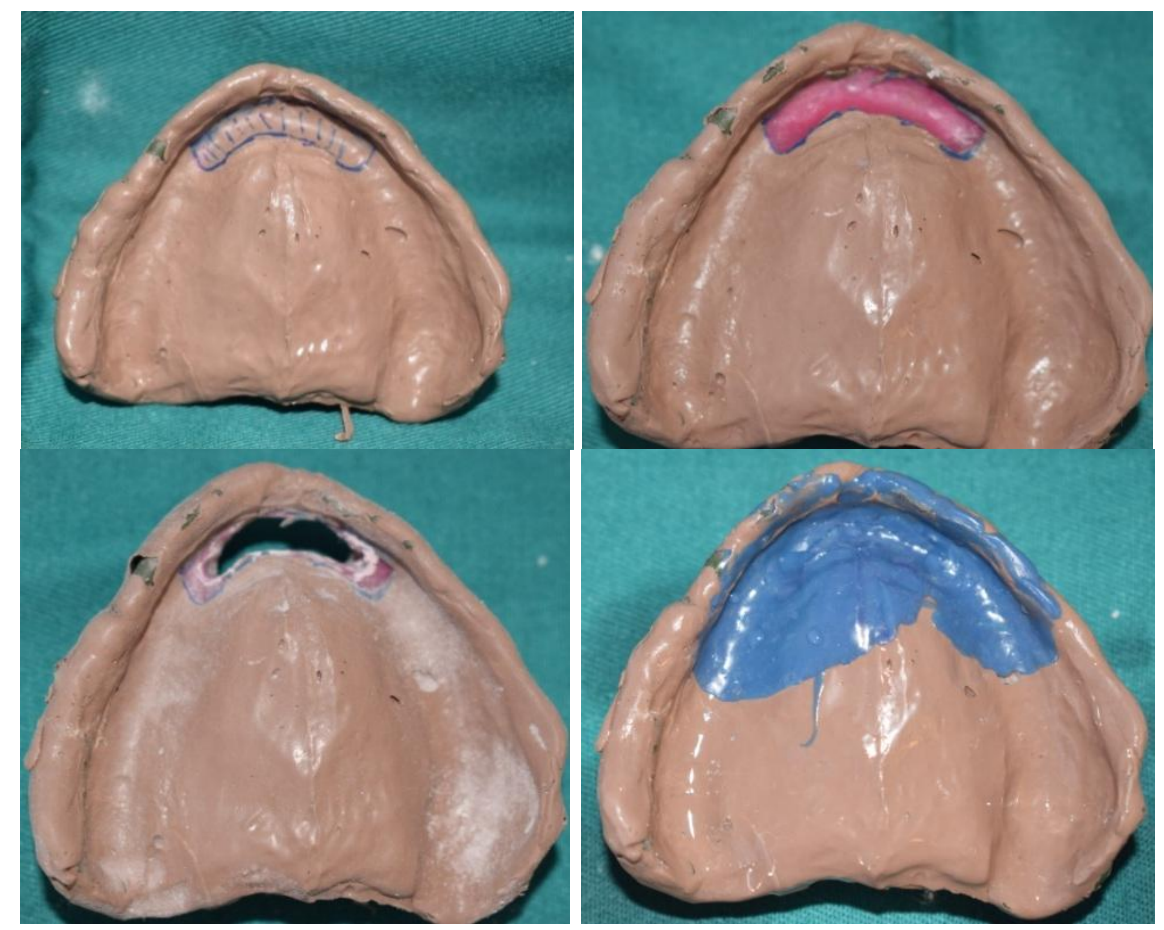

Fig-5: Secondary functional impression made with polyether and a low viscosity condensation silicone

The major second step in this case report was to make the lower primary impression to solve the unstable lower complete denture problem since all oral functions, such as speech, mastication, swallowing, smiling, and laughing, involve the synergistic actions of the tongue, lips, cheeks, and floor of the mouth which are very complex and highly individual [8].

Constructing satisfactory conventional mandibular complete dentures is often challenging in comparison to the upper counterpart partially due to differences in the anatomy of the denture-bearing area. This problem is exaggerated in the atrophic mandible, where supporting structures are frequently ill-defined and suboptimal in quality.
Implant-retained prostheses offer wellrecognized benefits but are not always a feasible option, so conventional methods must be relied upon.

The importance of impression quality and registration has been reviewed previously.

Many techniques have also been suggested using the materials in conjunction with movements including sucking, grinning and whistling, pursing the lips and speaking.

For the lower jaw a lead wire was wrought under the primary model 


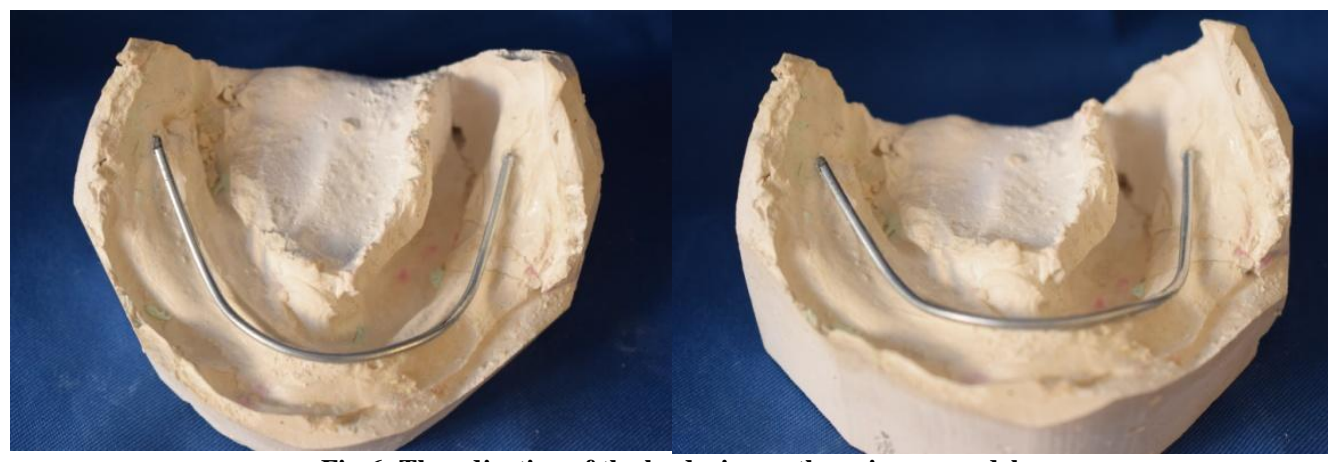

Fig-6: The adjusting of the lead wire on the primary model

This wire had to be stable on the model and the lower special tray was placed in the patient's mouth; this tray was very carefully adjusted in the mouth to be sure that it remains stable.

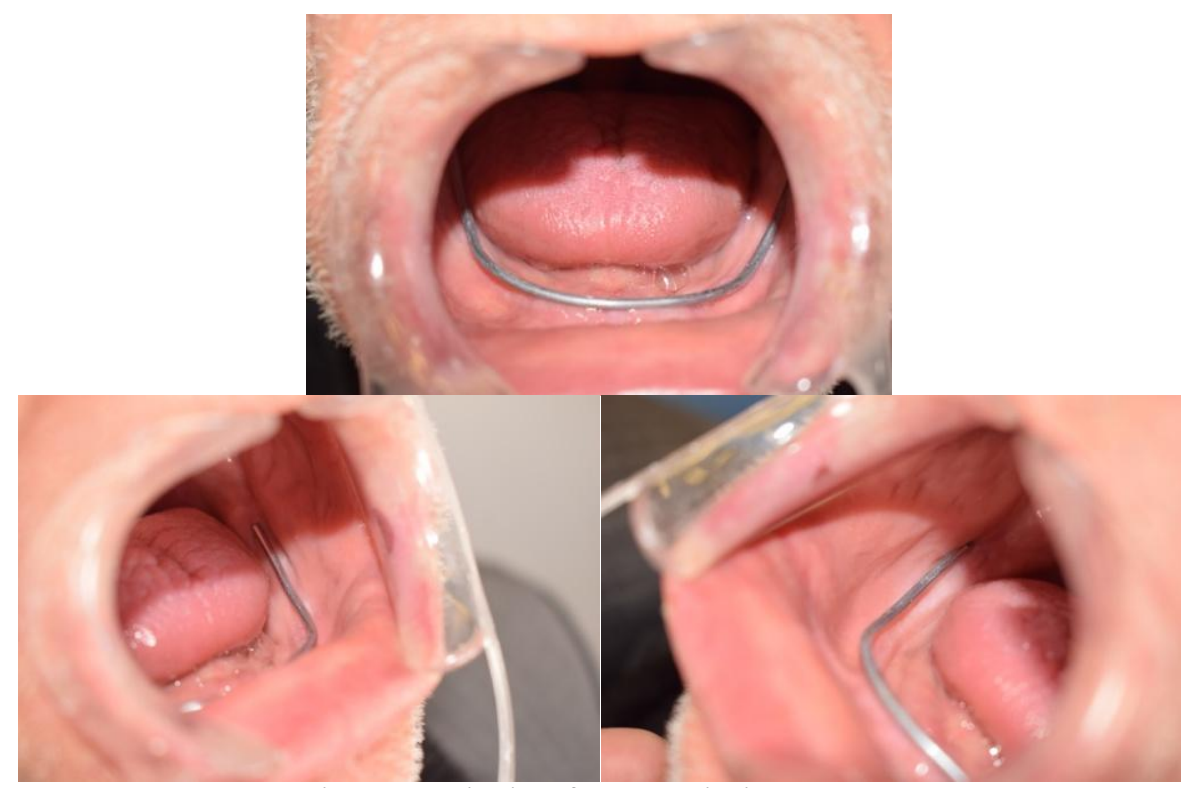

Fig-7: The adjusting of the lead wire in the mouth

The material used was the heavy -polyether viscosity; the idea was to proceed centimeter by centimeter; then to avoid that it stuck to fingers we used to put the material in a container with cold water; and the author proceeded to register the primary area using speech sequence (« $\mathrm{SO} »$ six times; « SIS » six times; « $\mathrm{SE}$ » six times again) interrupted with the swallowing function.

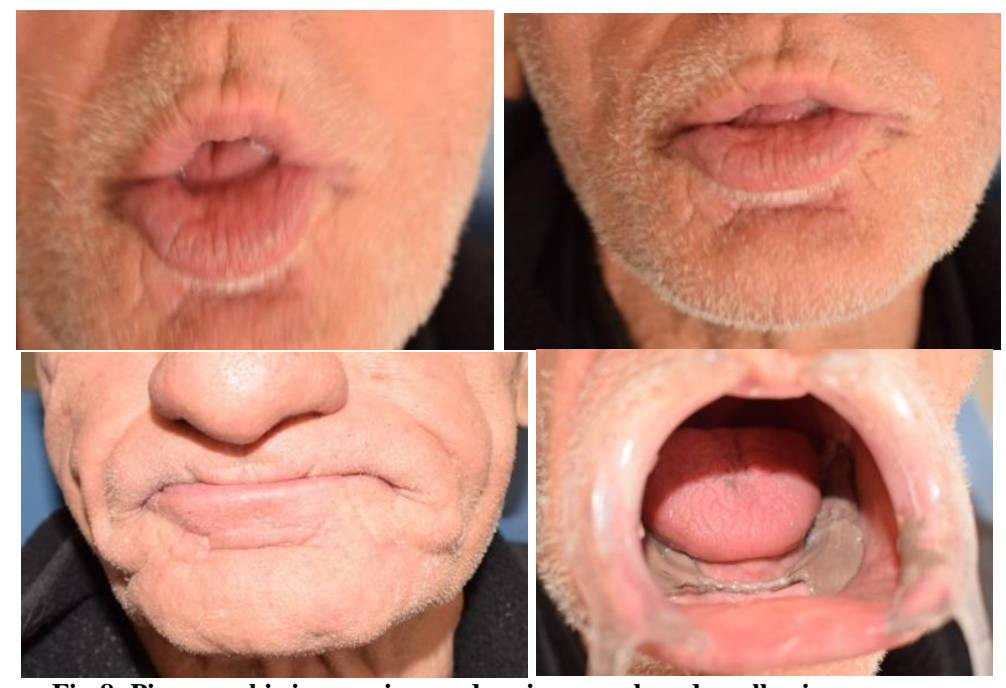

Fig-8: Piezographic impression made using speech and swallowing sequences 
The internal and external muscle groups have been brought into play, moving them through their respective action paths.

After some seconds; the set impression was removed from the mouth of the patient and examined and rectified if needed.
The second step of this preliminary impression is to make a surfacing with the impression material to be poured in the next time.
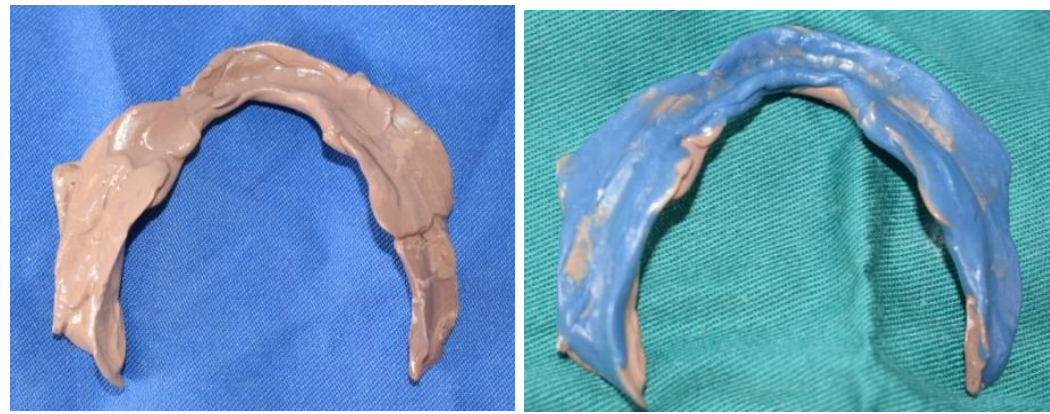

Fig-9: Impression surfacing with a low viscosity polyether

This new cast will lead the author to make a secondary impression as usually done in complete denture confection; and a new acrylic base was performed to start registering the neutral zone.

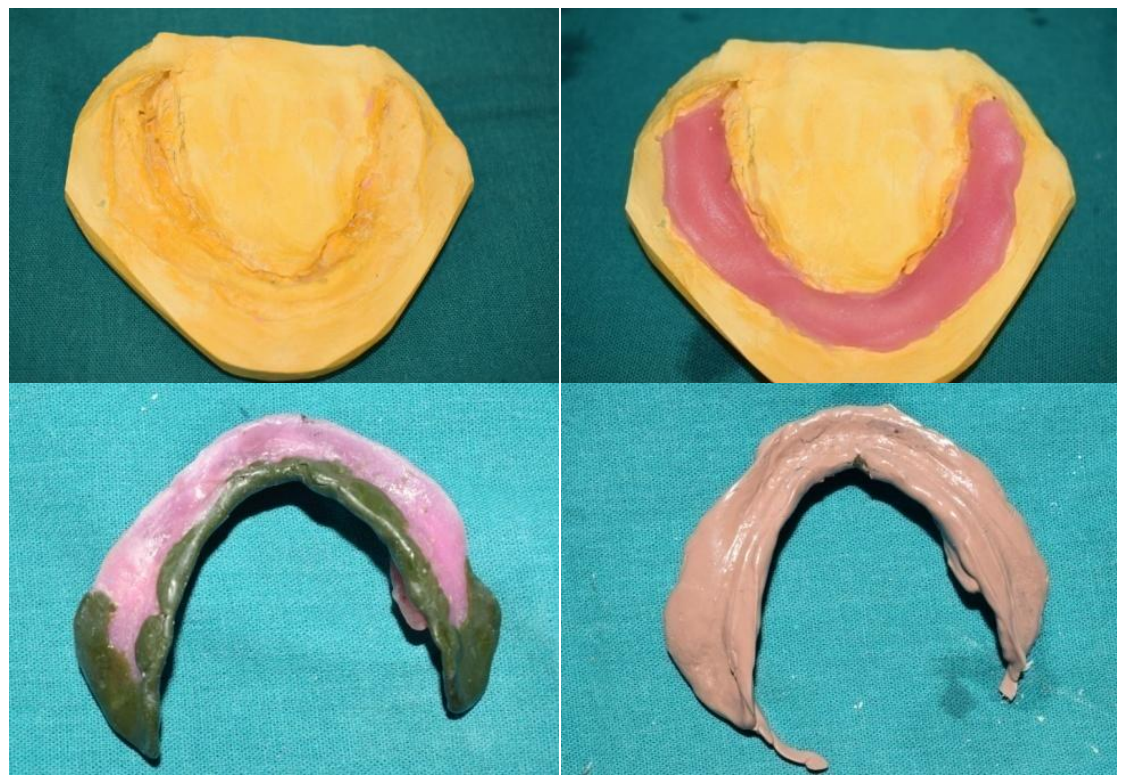

Fig-10: Second functional impression with functional margins formed with thermoplastic material

The central thesis of the neutral zone approach to complete dentures, is to locate that area in the edentulous mouth where the teeth should be positioned so that the forces exerted by muscles will tend to stabilize the denture rather than unseat it [5].

Much of modern literature focuses on implantrelated therapies. As the predictability of implants has improved greatly (and with accumulating amounts of associated evidence), the use of a two-implant retained mandibular overdenture has been deemed the treatment of choice for the unstable lower complete denture.

Unfortunately, in some circumstances, this is not always feasible and conventional methods must be relied upon [8].
Although some studies reported that their participants subjectively felt that neutral zone dentures were more stable, retentive, and comfortable with minimum problems after insertion and better esthetics than conventionally fabricated dentures, none of these studies used a measurable assessment scale or a specifically designed questionnaire [2].

\section{Piezography Procedure}

Fabricate mandibular occlusal rims over conventional record bases. The wax was punchedto hang the piezographic material. 


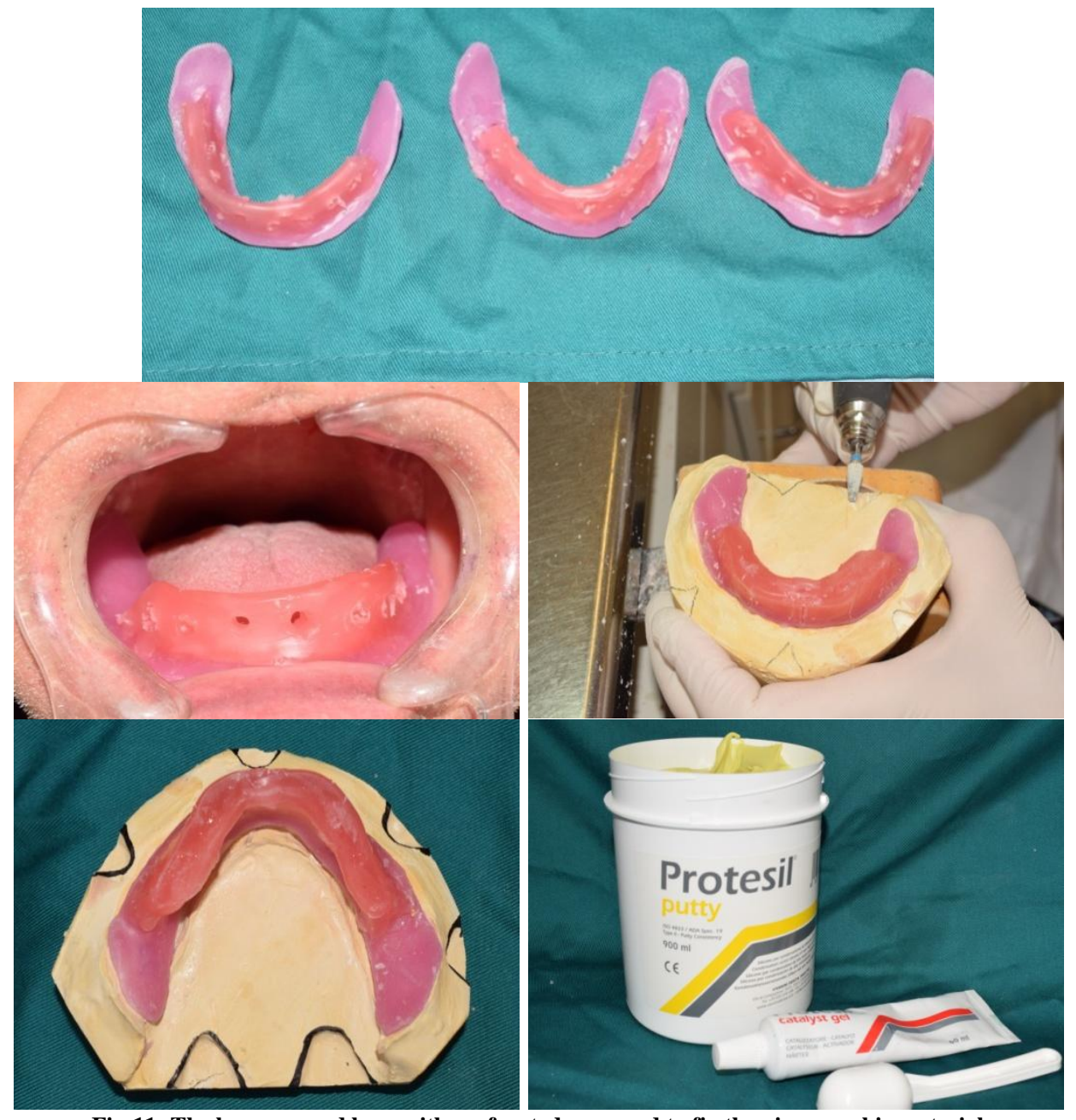

Fig-11: The lower record base with perforated wax used to fix the piezographic material

Register the mandibular neutral zone: All oral functions- speech, mastication, swallowing, smiling, laughing involve the synergistic actions of the tongue, lips, cheeks and floor of the mouth, which are very complex and highly individual in themselves.
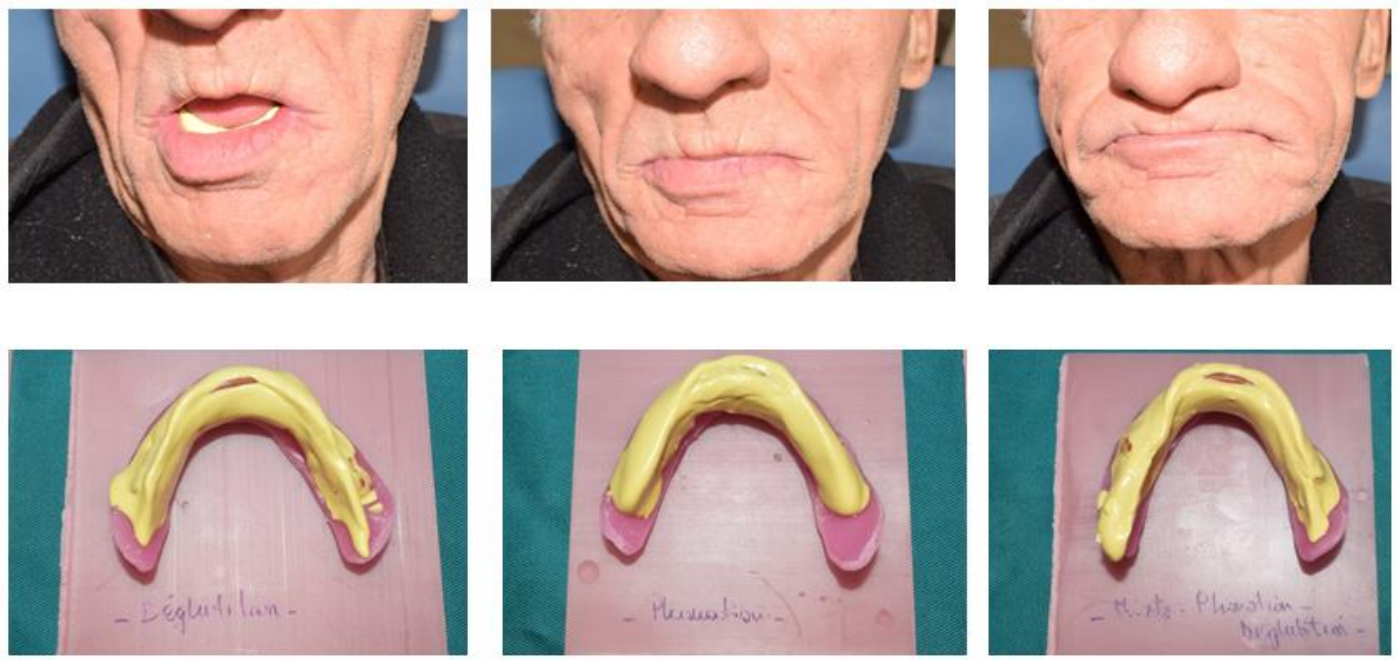

Fig-12: Three piezographs obtained with swallowing, phonetic and both functions 
That's why the author did compare neutral zone obtained from swallowing; speech and the mixed one as illustrated.

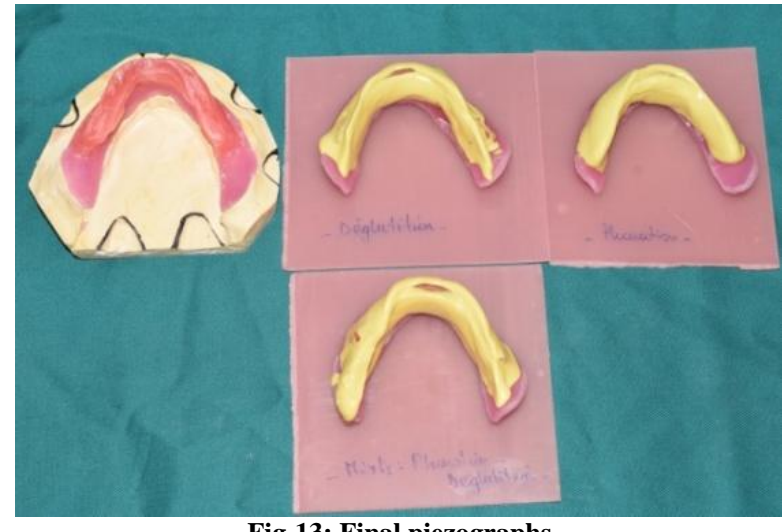

Fig-13: Final piezographs

Make the neutral zone indices with heavy silicone to facilitate artificial teeth arrangement.

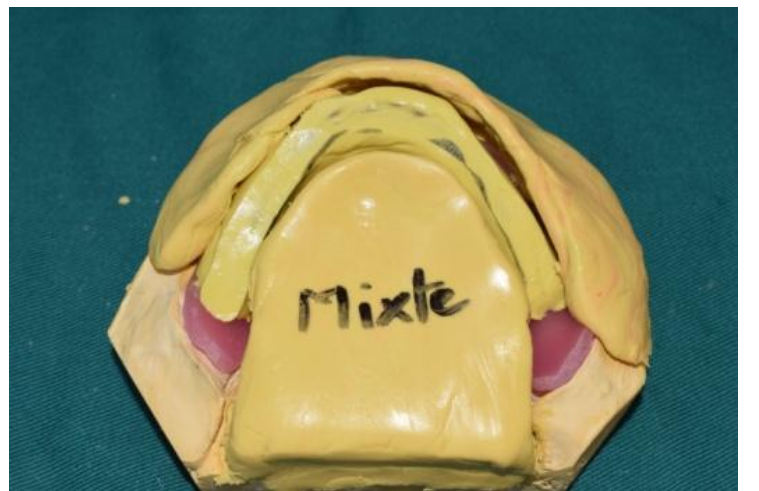

Fig-14: External surface contouring of maxillary and mandibular bases with addition silicon materia

After trial, carefully remove modeling wax apical to denture teeth facially, leaving sufficient wax to hold the teeth in position.

Wax try in was done and approved by the patient; after being confronted and examined on semi adjustable articulator (DENTATUS) then negotiated.
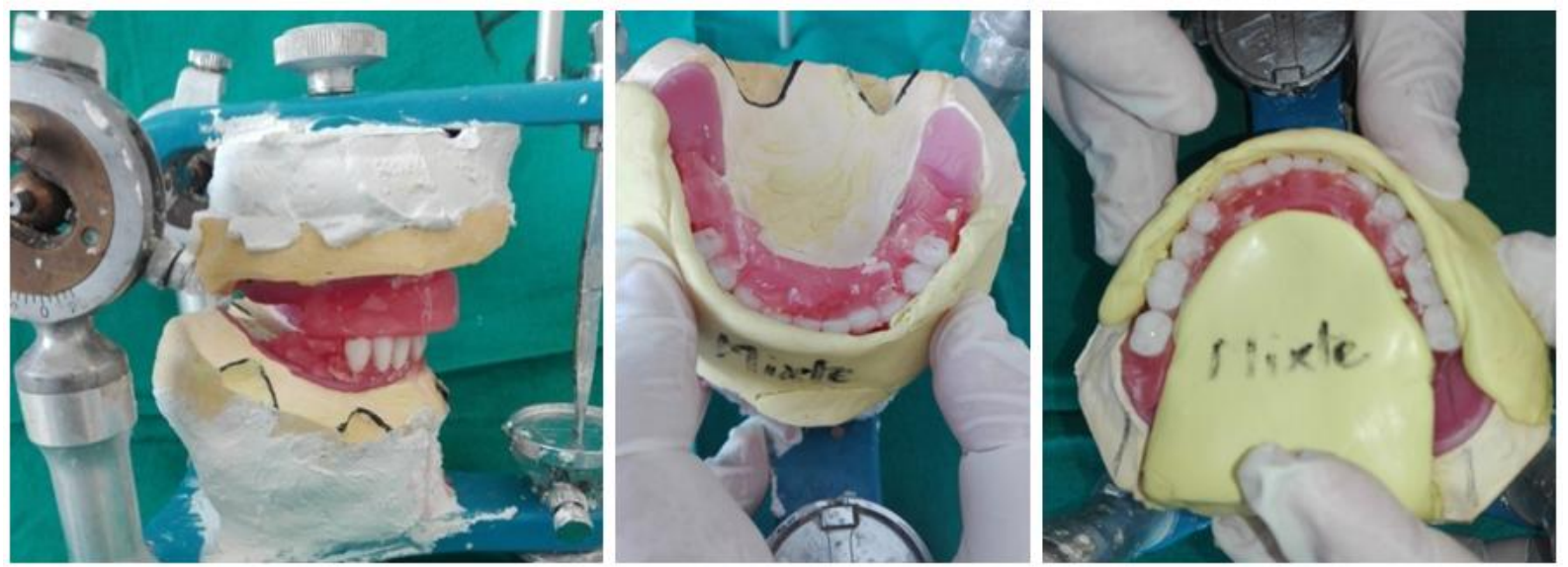

Fig-15: Maxillary and mandibular teeth arrangement within neutral zone indices

Follow this by conventional procedures of investment, processing, finishing and polishing [1].
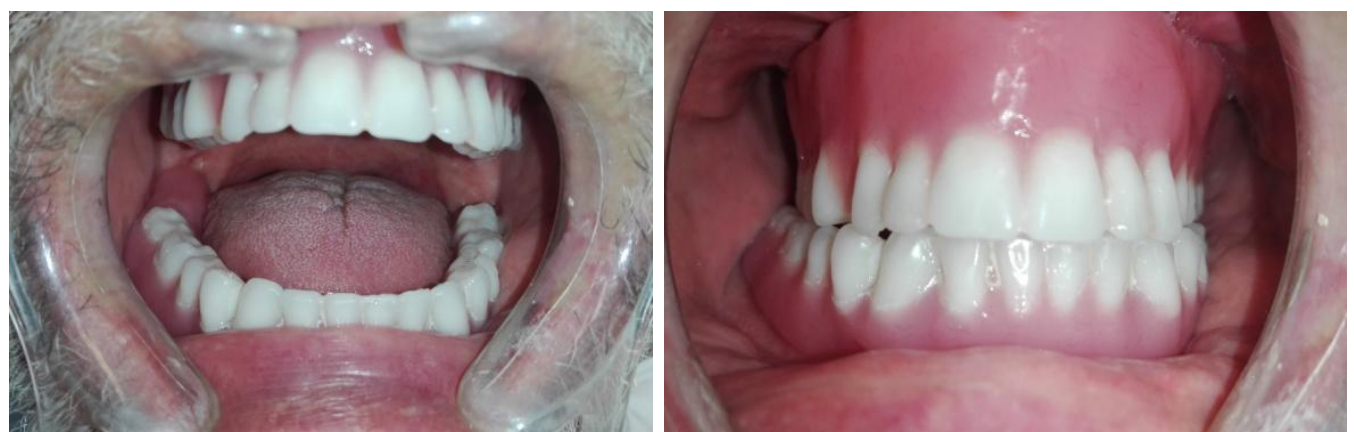

Fig-16: Processed maxillary and mandibular complete dentures 


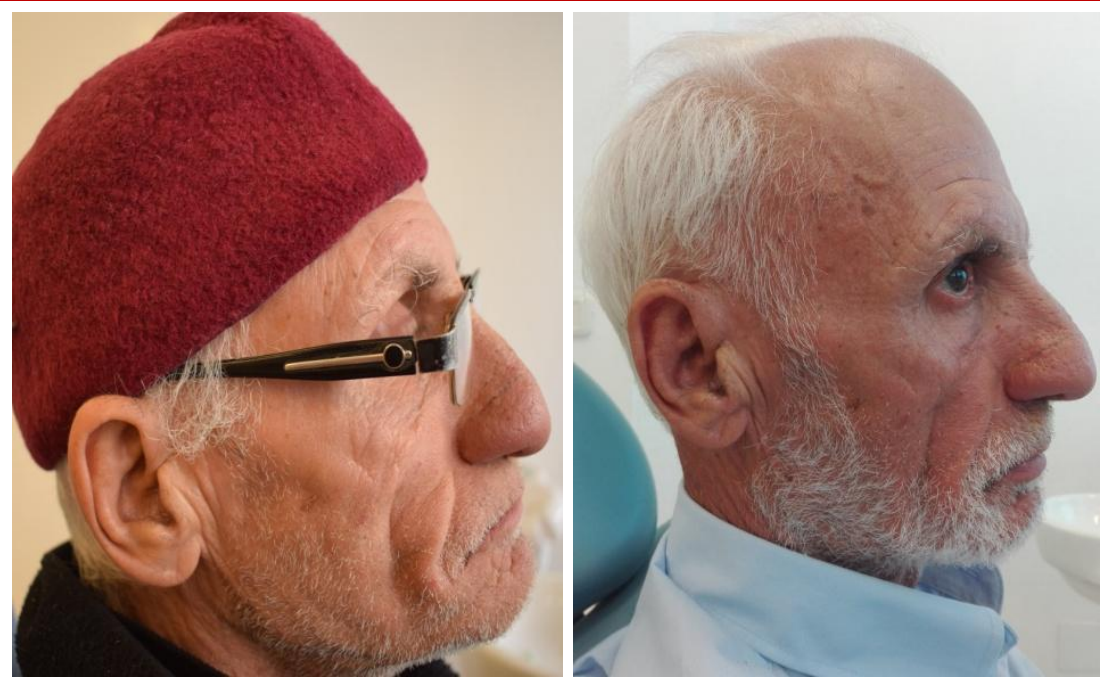

Fig-17: The final result

\section{DISCUSSION}

Dealing with highly resorbed madibular ridge has always been difficult for prosthodontists. Arranging teeth and contour of the complete denture within the neutral zone enhance prosthesis stability and improve comfort and function [1, 3-5.

Historically, several techniques have been described based on different oral functions. In 1931; Sir W. Fish was the first to expose the concept of dead zone describing the influence of the polished surface on retention and stability [10].

Heath, in 1947, confirmed that swallowing is adequate to mold the neutral zone instead of mastication, which couldn't carve piezography correctly, because of the masticatory muscles are disrupted [11].

In 1947, Klein used phonation to mold piezography because all the musculature works only in isotonic round, so this function could activate better the buccinator-labial belt, than deglutition $[4,12]$.

In 1984, Majdoub combined phonation to swallowing in order to activate the different antagonist muscular groups so "the balancing functional prosthodonticspace" is phonetically designed and then adapted to deglutition.

Piezography is still a relevant technique for treating highly resorbed mandibular ridge [4]. In fact, the other options of stabilizing denture by using implants is not always possible for patients who are medically compromised, anatomically deficient and economically depressed [7,9].

However, the neutral zone technique reminds technically difficult to manage because of extra-clinical steps involved and complexity requiring highly professional skills [14].

\section{CONCLUSION}

The three dimensional volume of complete dentures optimally occupies an edentulous space that is substantial, in the light of the progressive changes that accompany edentulism and functional dynamics.

Computer-aided design and computer-aided manufacturing (CAD-CAM) technology has been applied to complete denture fabrication. CAD-CAM dentures can be fabricated with high precision by reducing because polymerization distortion is eliminated [8].

After piezography; the space can be scanned, a virtual tooth arrangement and festooning can be performed within the space using computer-aided design software.

Using the piezography technique described, physiologically appropriate complete dentures can be fabricated based on the neutral zone concept.

\section{REFERENCES}

1. Agrawal, K. K., Singh, S. V., Vero, N., Alvi, H. A., Chand, P., Singh, K., \& Goel, P. (2012). Novel registration technique to register neutral zone. Journal of oral biology and craniofacial research, 2(3), 198-202.

2. Wafa'a, R., Swelem, A. A., Abdelnabi, M. H., \& Mofadhal, A. (2019). Effect on patient satisfaction of mandibular denture tooth arrangement in the neutral zone.The Journal of prosthetic dentistry, 121(3), 440-446.

3. Beresin, V. E., \& Schiesser, F. J. (2006). The neutral zone in complete dentures. Journal of Prosthetic Dentistry, 95(2), 93-100.

4. Bhattacharyya, J., Goel, P., Ghosh, S., \& Das, S. (2012). Piezography: An Innovative Technique in Complete Denture Fabrication. J Contemp Dent, 2(3), 109-113. 
5. Bhorgonde, D., Nandakumar, K., Khurana, P. R., Kumari, V. S., Reddy, M. S., \& Siddique, S. (2014). An evaluation of the position of the neutral zone in relation to the crest of mandibular alveolar ridge-An In-vivo study. Journal of international oral health: JIOH, 6(2):45-54.

6. Chandra, S. S. (2010). Management of a severely resorbed mandibular ridge with the neutral zone technique. Contemporary clinical dentistry, 1(1), 36-39.

7. Jain, C., Goel, R., Kumar, P., \& Singh, H. P. (2011). Neutral zone approach for severely atrophic ridges; Avenues beyond implants and surgeries-A case report. International Journal of Clinical Dental Science, 2(3):33-35.

8. Clarke, P., Leven, A. J., \& Youngson, C. C. (2016). Managing the unstable mandibular complete denture-tooth placement and the polished surface. Dental update, 43(7), 660-670.

9. Cooper, L., Rosen, A., \& Duqum, I. (2004). Implant supported overdenture options for the edentulous patient. Int Dent SA, 13(1), 12-16.

10. Fish, E. W. (1931). An analysis of the stabilizing factors in full denture constructions. British Dental Journal. 2:559-570.
11. Heath, R. (1970). A study of the morphology of the denture space. Dent Prac Dent Rec, 21:109117.

12. Klein, P. (1988). Prothèse piézographique. Prothèse adjointe gériatrique. John Libbey. London. Paris.

13. Kršek, H., \& Dulčić, N. (2015). Functional Impressions in Complete Denture and Overdenture Treatment. Acta Stomatol Croat. 49(1):45-53.

14. Saba, N., Nath, D. K., \& Gupta, P. (2013). Neutral zone technique for the management of unstable mandibular complete denture: A case Report. Journal of Dental Sciences and Oral rehabilitation: 44-46.

15. Tayari, O., Haloui, H., Jaouadi, J., \& Ben Rahma, A. (2018). Final impression in complete dentures. Dental News. 25(4):24-30.

16. Ohkubo, C., Shimpo, H., Tokue, A., Park, E. J., \& Kim, T. H. (2018). Complete denture fabrication using piezography and CAD-CAM: A clinical report. The Journal of prosthetic dentistry, 119(3), 334-338. 